Hussein, S., Manthorpe, J. and Harris, J. (2011) Do the characteristics of seconded or sponsored social work students in England differ from those of other social work students? -A quantitative analysis using national data. Social Work Education, the International Journal, 30(3): 345-359.

\title{
Do the characteristics of seconded or sponsored social work students in England differ from those of other social work students? - A quantitative analysis using national data
}

\section{Shereen Hussein, Jill Manthorpe and Jess Harris}

\begin{abstract}
Amongst initiatives by social work employers in the United Kingdom (UK) to resolve recruitment difficulties is the use of secondment and sponsorship to attract entrants to the profession; commonly known as Grow Your Own Schemes. This paper reports on part of a mixed-method research study that asked 'What works in Grow Your Own (GYO) schemes?' in England. One important research question for this study was whether the characteristics of seconded or sponsored social work students differ from those of other social work students. To explore this, the researchers analysed around 41,000 students' anonymous data records supplied by the General Social Care Council covering enrollments on social work programmes from 1998 to 2007. The findings indicate that GYO schemes have facilitated the participation of men, Asian groups and older applicants in social work qualifying programmes when compared to the general population of social work students. However, students from Black ethnic backgrounds and those with disabilities have been more likely to be under-represented in such schemes. The findings are discussed within the wider study remits and messages for educationalists and social work employers are drawn out.
\end{abstract}

Keywords: Employer-based Training; Large Dataset; Secondment; Sponsorship; Social Work Students; Student Characteristics

\section{Introduction}

There is a shortage of good quality social workers working with children, families and adults in the United Kingdom (UK) according to a government commissioned report on access to the professions (Langlands, 2005). This reflects longstanding high levels of social work vacancies and turnover. One objective of the Strategy for Social Care was to increase the numbers in social work training (Department of Health, 2000) and the government's review Options for Excellence, explored ways to increase social workers' supply (Department of Health/ Department for Education and Skills, 2006).

Social work employers (in England mainly local authorities) have attempted to resolve recruitment difficulties through improving pay and conditions; recruiting social workers from outside the UK (Hussein et al. 2010; Moriarty et al., 2008); and financial incentives such as secondment and sponsorship to 
attract entrants to the profession. These terms are sometimes used interchangeably, but essentially they are schemes by which employers fund existing staff to undertake professional training or funding individuals within a contractual relationship whereby funding is 'exchanged' for commitment to work for the employer on qualification and/or during study. Despite these longstanding arrangements, research is sparse, but reports of such initiatives indicate their popularity (authors).

GYO schemes are proactive ways to address social work shortages. There are underlying assumptions that they enable non-traditional students to pursue qualifications. What are defined as 'traditional' or 'non-traditional' groups may differ across specific subjects and professions. Social work students as a whole are characterized by a higher average age than that of students overall with many more females than males (Evaluation of Social Work Degree Qualification in England Team, 2008). Social work appears to attract a broader range of students in terms of educational background than other professions (Hussein et al., 2008; 2009). However, other characteristics may be important in determining whether a staff member is offered the opportunity or whether an employer chooses to invest in a particular applicant. For example, length and type of employment are important factors in improving the chances of secondment in all work sectors, not just social work. Employees with medium-term length of employment (1-5 years) and with permanent contracts are more likely to be trained than those with shorter lengths of tenure or temporary contacts (O'Connell, 2007). Employers' own characteristics influence whether opportunities for sponsorship or secondment are available. Lassnigg and colleagues (2007) observed that the sector and size of employer determine their attitudes towards investment in workforce training.

At the same time, widening access to higher education in the UK has been a government objective, with the Robbins Committee (1963) marking the beginning of the mass expansion of higher education, and the establishment of the Open University in 1969. The Dearing Report (1997) recommended that government should award priority to HEls (Higher Education Institutionsuniversities and colleges of higher education) demonstrating a commitment to widening participation. Closely allied are initiatives to sustain and improve diversity in the social work profession. The Langlands Report (2005) highlighted, although with little evidence, continuing difficulty in recruiting students representative of the diversity of localities and the ambitions for a diverse social work profession consider it ultimately benefits service users (Hafford-Letchfield, 2007).

It is in this context that this study of Grow Your Own (GYO) social work education was situated. This umbrella term is useful because the terminology of employment-based routes and employment supported routes to professional training in social work is confusing and terms like secondment and sponsorship are used interchangeably. Employers may run schemes in parallel or select elements from each model, reflecting different organisational priorities. All these factors have implications for individual students' experiences and wider organisational impact. The main GYO programme in 
the UK leading to a social work qualification, the National Open Learning Programme, has been offered by the Open University since 1997. Most students undertake placements in their employing organisation (work-based placements). Together these initiatives may be termed 'employment-based' routes to a social work qualification, where employers fund students through payment of fees and/or study time, as a long-established approach to addressing recruitment pressures as mentioned above (Balloch, 1999; Payne, 2005; Dunworth, 2007). However, they are characterized by evolving models and varying levels of availability. More recently, the investment in graduate trainee candidates, explicitly from outside the social care workforce, has been promoted by government as postgraduate sponsorship schemes in England (Department for Children, Schools \& Families, 2008).

As part of this study we investigated the common characteristics, if any, of individuals who make successful applications to GYO schemes. Whether those who access GYO schemes are more likely to possess specific personal characteristics, related to age, gender or ethnicity, for example, than other social work students is the focus of this paper.

\section{Methods}

This paper reports on a part of a mixed-method study examining motivations and experiences of employers, HEls and students in running, supporting and participating in GYO schemes. The objectives were to build an evidence base, to better understand some of the implications and the impact of this route to social work qualification. The study undertook interviews with employers, HEls, and with GYO students (authors); two national stakeholders' events exploring and discussing issues around GYO schemes as well as quantitative data analysis of students' records from the General Social Care Council (GSCC) student registration data set. This paper reports on the latter part of study, focusing on the question of whether GYO students' characteristics differ from other social work students who do not receive employers' support.

The data included records of undergraduate and postgraduate students enrolled for social work qualifications from 1998-2007 providing information on around 41,000 students. Each student's record includes personal details such as date of birth, gender, ethnicity, highest previous educational attainment, funding source, any self-reported disability, as well as the name of the HEI, its geographical location, mode of study, programme type and source of funding, thus allowing the identification of students on GYO schemes (namely those declaring themselves as seconded or sponsored by their employers). This was a unique source of information on the characteristics of social work students in England covering nearly a decade, and offered an unprecedented opportunity to understand the composition and trends of GYO students. It enabled the first comparisons between GYO students and students with other sources of funding, mainly bursaries and grants. We used a variety of bivariate and multivariate analyses to examine variations in the probability of students being on GYO schemes. 


\section{Findings}

Table 1 presents the distribution of students identified as being seconded or sponsored by employers, and those who were not, by different characteristics and year of registration on the previous Diploma in Social Work (DipSW) or the social work degree, which spanned 1998-2007 as the qualification for social work in England. The proportion of students on GYO schemes (seconded or sponsored) ranged from 9 percent to an astonishing 40 percent during the last intake of the DipSW 2003-2004, with an overall average of 20 percent across the ten cohorts. A full analysis of levels and trends of students benefiting from GYO schemes is provided elsewhere (authors). Here, in the next subsections we discuss the variations in the prevalence of GYO schemes among different groups of students according to their characteristics.

\section{Gender}

It is well known that women are over-represented as social work students as a whole, with the percentage of male (GYO and non-GYO) social work students falling yearly from 22 percent in 1998 to 15 percent of students in 2006 (Evaluation of Social Work Degree Qualification in England Team, 2008). By contrast, the proportion of men on GYO schemes has been consistently higher than among non-GYO students, although this has been declining over the past decade. In the last six years of the DipSW, 1998-2004, the percentage of GYO students who were men fell consistently from 29 to 21 percent, compared to a fall from 21 to 18 percent for non-GYO men students. However, more recently, in the four first years of the new degree, the proportion of men on GYO schemes increased slightly, to reach 22 percent, whilst levels of men amongst non-GYO students declined slightly from 16 to 14 percent.

Using Pearson Chi-square and Fisher Exact Tests, the differences in the distribution of GYO students by gender were significant on $p<0.005$ with few exceptions. During the last DipSW cohort these differences were not significant and during the two first cohorts of the new degree such differences were only of borderline significance. This means that there were more or less equal distributions of men and women among those who were seconded or not during these three cohorts. However, men became significantly over represented again among those who were seconded during the latest two cohorts of the new degree (05-06 and 06-07) for which data were available.

\section{Age}

Prior to the introduction of the new degree, the mean, or average, age of all social work students (GYO and non-GYO) was rising, from 32.6 years in 1998-99 to 42.5 years among the final DipSW cohort in 2003-04. The mean age of the first cohort of the new degree dropped sharply to 31.8 years and started a declining trend to reach 29.8 years for the latest cohort of 2006-07 about which data are available at the time of writing (such differences were significant: $\underline{F=155.6 ;} p<0.001)$. 
Table 1 Distribution of students registering to social work courses according to whether being seconded or sponsored by their employers and personal characteristics by year of registration and type of award, 1998-2007

\begin{tabular}{|c|c|c|c|c|c|c|c|c|c|c|c|c|c|c|c|}
\hline $\begin{array}{l}\text { Year and award } \\
\text { and whether on } \\
\text { GYO schemes or } \\
\text { not }\end{array}$ & Women & Men & $\begin{array}{l}\text { White } \\
\text { (UK) }\end{array}$ & $\begin{array}{l}\text { White } \\
\text { (Other) }\end{array}$ & Asian & Black & Other & $\begin{array}{l}\text { Rep } \\
\text { disal }\end{array}$ & Any & $\begin{array}{c}\text { O level } \\
\text { or equ }\end{array}$ & $\begin{array}{c}\text { Educa } \\
\text { A } \\
\text { level } \\
\text { or } \\
\text { equ }\end{array}$ & on at start & Degree & $\begin{array}{c}\text { Mean } \\
\text { age at } \\
\text { start } \\
\end{array}$ & $\begin{array}{c}\text { Number } \\
\text { of } \\
\text { students }\end{array}$ \\
\hline \multicolumn{16}{|l|}{ Non-GYO students } \\
\hline DipSW 98-99 & $79 \%$ & $21 \%$ & $79 \%$ & $2 \%$ & $5 \%$ & $12 \%$ & $3 \%$ & $90 \%$ & $10 \%$ & $9 \%$ & $32 \%$ & $25 \%$ & $34 \%$ & 31.8 & 3522 \\
\hline DipSW 99-00 & $79 \%$ & $21 \%$ & $78 \%$ & $2 \%$ & $5 \%$ & $12 \%$ & $4 \%$ & $90 \%$ & $10 \%$ & $8 \%$ & $31 \%$ & $24 \%$ & $37 \%$ & 32.0 & 3374 \\
\hline DipSW 00-01 & $81 \%$ & $19 \%$ & $78 \%$ & $1 \%$ & $5 \%$ & $11 \%$ & $4 \%$ & $89 \%$ & $11 \%$ & $7 \%$ & $33 \%$ & $22 \%$ & $39 \%$ & 32.3 & 3132 \\
\hline DipSW 01-02 & $83 \%$ & $18 \%$ & $76 \%$ & $2 \%$ & $5 \%$ & $12 \%$ & $5 \%$ & $90 \%$ & $10 \%$ & $7 \%$ & $33 \%$ & $24 \%$ & $35 \%$ & 32.6 & 3265 \\
\hline DipSW 02-03 & $84 \%$ & $16 \%$ & $75 \%$ & $2 \%$ & $4 \%$ & $14 \%$ & $4 \%$ & $88 \%$ & $12 \%$ & $7 \%$ & $35 \%$ & $23 \%$ & $35 \%$ & 32.8 & 3548 \\
\hline DipSW 03-04 & $82 \%$ & $18 \%$ & $75 \%$ & $2 \%$ & $7 \%$ & $12 \%$ & $4 \%$ & $89 \%$ & $11 \%$ & $6 \%$ & $25 \%$ & $16 \%$ & $54 \%$ & 32.3 & 1867 \\
\hline Degree 03-04 & $84 \%$ & $16 \%$ & $70 \%$ & $3 \%$ & $5 \%$ & $17 \%$ & $5 \%$ & $89 \%$ & $11 \%$ & $7 \%$ & $53 \%$ & $27 \%$ & $13 \%$ & 31.0 & 2171 \\
\hline Degree 04-05 & $84 \%$ & $16 \%$ & $69 \%$ & $3 \%$ & $6 \%$ & $18 \%$ & $5 \%$ & $90 \%$ & $10 \%$ & $5 \%$ & $46 \%$ & $23 \%$ & $27 \%$ & 29.7 & 3860 \\
\hline Degree 05-06 & $85 \%$ & $15 \%$ & $71 \%$ & $3 \%$ & $5 \%$ & $18 \%$ & $4 \%$ & $90 \%$ & $10 \%$ & $4 \%$ & $47 \%$ & $19 \%$ & $31 \%$ & 29.2 & 4114 \\
\hline Degree $06-07 \dagger$ & $86 \%$ & $14 \%$ & $69 \%$ & $2 \%$ & $6 \%$ & $20 \%$ & $4 \%$ & $96 \%$ & $5 \%$ & $2 \%$ & $46 \%$ & $21 \%$ & $31 \%$ & 29.0 & 3698 \\
\hline \multicolumn{16}{|l|}{ GYO students } \\
\hline DipSW 98-99 & $71 \%$ & $29 \%$ & $82 \%$ & $2 \%$ & $4 \%$ & $9 \%$ & $2 \%$ & $92 \%$ & $9 \%$ & $20 \%$ & $23 \%$ & $35 \%$ & $23 \%$ & 38.0 & 588 \\
\hline DipSW 99-00 & $72 \%$ & $28 \%$ & $81 \%$ & $0 \%$ & $6 \%$ & $10 \%$ & $3 \%$ & $91 \%$ & $9 \%$ & $16 \%$ & $23 \%$ & $35 \%$ & $26 \%$ & 38.1 & 726 \\
\hline DipSW 00-01 & $74 \%$ & $26 \%$ & $82 \%$ & $2 \%$ & $5 \%$ & $9 \%$ & $3 \%$ & $92 \%$ & $8 \%$ & $17 \%$ & $26 \%$ & $35 \%$ & $23 \%$ & 37.8 & 805 \\
\hline DipSW 01-02 & $77 \%$ & $23 \%$ & $78 \%$ & $3 \%$ & $6 \%$ & $10 \%$ & $3 \%$ & $90 \%$ & $10 \%$ & $15 \%$ & $27 \%$ & $33 \%$ & $25 \%$ & 38.3 & 1011 \\
\hline DipSW 02-03 & $78 \%$ & $22 \%$ & $80 \%$ & $3 \%$ & $4 \%$ & $10 \%$ & $3 \%$ & $90 \%$ & $10 \%$ & $14 \%$ & $30 \%$ & $30 \%$ & $27 \%$ & 38.1 & 1204 \\
\hline DipSW 03-04 & $79 \%$ & $21 \%$ & $80 \%$ & $3 \%$ & $4 \%$ & $9 \%$ & $3 \%$ & $91 \%$ & $9 \%$ & $14 \%$ & $29 \%$ & $26 \%$ & $31 \%$ & 37.9 & 1260 \\
\hline Degree 03-04 & $78 \%$ & $22 \%$ & $71 \%$ & $3 \%$ & $5 \%$ & $17 \%$ & $4 \%$ & $90 \%$ & $10 \%$ & $13 \%$ & $34 \%$ & $31 \%$ & $22 \%$ & 37.6 & 322 \\
\hline Degree 04-05 & $80 \%$ & $20 \%$ & $76 \%$ & $4 \%$ & $7 \%$ & $11 \%$ & $3 \%$ & $90 \%$ & $10 \%$ & $10 \%$ & $34 \%$ & $25 \%$ & $32 \%$ & 36.1 & 701 \\
\hline Degree 05-06 & $79 \%$ & $21 \%$ & $78 \%$ & $4 \%$ & $5 \%$ & $10 \%$ & $4 \%$ & $90 \%$ & $10 \%$ & $10 \%$ & $30 \%$ & $25 \%$ & $35 \%$ & 36.4 & 1294 \\
\hline Degree $06-07 \dagger$ & $78 \%$ & $22 \%$ & $80 \%$ & $3 \%$ & $6 \%$ & $8 \%$ & $4 \%$ & $95 \%$ & $5 \%$ & $2 \%$ & $28 \%$ & $19 \%$ & $52 \%$ & 35.5 & 379 \\
\hline
\end{tabular}

$\dagger$ At the time of analysis data for 2006-07 were missing information relating to the Open University. 
GYO students (seconded or sponsored) were consistently older than nonGYO students for all the DipSW and new degree academic cohorts in the period 1998-2007. Over this time students who were seconded had the highest mean age, ranging from 36.5 to 38.7 years, while the mean age among those who were sponsored was only slightly lower, ranging from 35.8 37.7 years. In contrast, the mean age ranged from 29.1 to 32.8 years among non-GYO students (data not shown in the table).

Among DipSW students from 1998-2004, seconded students were on average 6.1 years older, and sponsored students 5.2 years older, than nonGYO students. Since the start of the new degree this age gap has widened slightly, with both seconded and sponsored students on average 7 years older than non-GYO students. This increasing age difference reflects the withdrawal of a minimum qualifying age of 22 years, and the fact that GYO students are more likely to have work experience in social care prior to entering study.

\section{Self-reported disabilities}

Students' registration data include information on whether they consider themselves to have a disability. It should be noted that this measure of disability is not an indication of whether students have declared this to employers, or are receiving financial support through Disabled Students' Allowances. There are some limitations to this information: firstly, students tend not to respond to provide information on their disability in comparison to other information, with nine percent not providing information about their disability status compared to 0.1 percent not providing information on gender or age. Secondly, information on disability is collected at the onset of courses, but some students may discover, or disclose, a disability during their studies. Some social work students and professionals choose not to disclose unseen disabilities; for fear that these will damage employment opportunities or progression (Stanley et al., 2007).

Nevertheless, GSCC records provide the most accurate data available about disability levels among social work students at the time of enrollment. Our analysis considered if students reported any form of disability, which may be a physical impairment or any unseen form of disability, such as mental health problems or dyslexia. The proportion of all social work students (GYO and non-GYO) with a self-reported disability was almost uniform across all cohorts $(1998-2007)$ at around one tenth. An exception was the most recent cohort of the degree, 2006-2007, where only 5 percent of students reported any form of disability. Whether this represents a trend or not will have to be determined.

Table 1 shows that the proportion of students with any self-reported disability was slightly lower among GYO students prior to the introduction of the new degree, with almost no difference since its onset: GYO students reporting a disability ranged between 8 to 10 percent, compared to between 10 to 12 percent amongst non-GYO students.

\section{Ethnicity}

The analysis shows that before the introduction of the new degree the overall distribution was almost constant with White UK students forming from 76 to 79 
percent of students, White Other form two to three percent, Asian around 5 percent, Black from 11 to 13 percent and Mixed and Other ethnicities less than 5 percent. The first years of the new degree, 2003-07, saw a marked increase in the proportion of students identifying themselves as Black (16 to 18 percent) with a corresponding drop in White UK students (69 to 72 percent).

In relation to distribution among GYO and non-GYO groups, Table 1 shows that in some years the ethnic distributions of both groups are similar but particularly recently, there are clearer differences between GYO and other students. These mainly relate to the higher representation of White UK students and the lower representation of Black students among GYO students since the full roll-out of the new degree (2004-05).

To examine whether these differences were significant we used Chi-Square tests that confirmed such observations are significant for all the new degree cohorts except the first (2003-04) when less than half HEls offering social work ran the new degree. Significant differences in the ethnicity distributions were observed on the last two cohorts of the DipSW (2002-03 and 2003-04). These were similarly related to a higher representation of White UK students and a lower representation of Black students among GYO students. Parallel observations were noted during some earlier DipSW cohorts (namely 1999-00 and 2000-01), however on a lower significance level $(p<0.05)$, indicating that such variations are long-established and appear to be strengthening with time, consistent with other research (Wallis-Jones \& Lyons, 2001).

\section{Educational background}

Education level at registration time was recoded ${ }^{1}$ to: ' $O$ ' level or equivalent, ' $A$ ' level or equivalent, Diploma, and any previous degree; however a small proportion $(6 \%)$ of students registered did not provide this information.

For all social work students (GYO and non-GYO) a declining trend in the proportion of students entering social work with only ' $O$ ' level or equivalent was observed (from 11\% in 1998-99 to only 3\% in 2006-07). In contrast, a relatively large proportion of students enter social work education with a previous degree (consistently over 30\% between 1998-2003). This proportion fluctuated around the transition from DipSW to the new degree, with a higher than average proportion of students with a previous degree enrolled for the final DipSW cohort. This may be linked to the surge of secondment rates observed during the same year, as explored later in this section. During the last DipSW cohort (2003-04) 44 percent of students had a previous degree in comparison to 32 percent the previous year and only 15 percent undertaking the new degree during the same academic year. Since the introduction of the new degree an increasing trend in the proportion of students who have ' $A$ ' levels or equivalent was observed. Again, this may be linked to the fact that since the introduction of the new degree students tend to be younger, in line with the rise in applications to study social work and the ability of admissions tutors to be more selective (Manthorpe et al. advance access a).

\footnotetext{
1 'O level or equivalent': O level, NVQ 2 and Non-certified learning; 'A level or equivalent': A level, NVQ3 and NVQ4, 'Diploma': higher or other Diploma, Degree; Degree.
} 
Looking at previous educational attainment amongst all social work students, Table 1 indicates some distinctive trends in the levels of previous educational attainment of GYO students 1998 - 2007. Chi-square tests confirm that all these differences are significant on $p<0.005$, i.e. not due to error or chance. However, the patterns of differences in these educational distributions vary dramatically following the replacement of the DipSW by the new degree.

In summary, GYO students before the introduction of the new degree tended to be less educationally qualified than their non-GYO peers. Since the new degree GYO students are significantly more likely to hold higher educational qualification than non-GYO students, with increasingly larger proportions of GYO students already possessing a degree than non-GYO students (between 22 and 52 percent of GYO students compared to 13 and 31 percent of nonGYO students).

At the introduction of the new degree there remained relatively higher proportions of GYO students with the lowest level of previous qualifications, 'O' level or equivalent (13\%). This has since declined over the four academic cohorts to the same level as non-GYO students, at only 3 percent of students in 2006-07.

\section{Variations in the characteristics of GYO students}

Above we showed how students' characteristics vary between those who were GYO students or not, with several patterns and differences distinguishable before and after the introduction of the new degree. In this section we develop understanding of how these different characteristics interact with and influence the profile of GYO students. We use regression models to examine interactions and we focus on the new degree; analyses related to the former DipSW are presented in the full report (authors), however, findings for both groups are compared for illustration.

\section{New degree (2003-2007) and GYO}

To examine the association between all students' characteristics and the probability of being a GYO student since the introduction of the new degree a binary logit regression model was constructed. The outcome of this model is 'student being seconded or sponsored' and all students' characteristics, as well as region, cohort, programme type and whether students were registered as full or part time are used as explanatory variables.

Table 2 presents the results of this model: all explanatory variables included in the model are listed in the table; significant ones being highlighted. The results reveal some significantly associated factors with the probability of a student to be on a GYO scheme among those undertaking the new degree. Some of these factors are similar to those during the DipSW, however, some new factors are emerging as more significant influences on the chances of participating in GYO schemes following the new degree; these are highlighted at the end of this section (summarised in Table 3).

Similar to the DipSW, men and older students were significantly more likely to be GYO than non-GYO students on the new degree; moreover, the impact of each year of age became stronger during the new degree (each year adds $6 \%$ more chance of being seconded or sponsored vs. $5 \%$ under the DipSW). 
On the other hand, while controlling for other variables, the effect of gender is becoming slightly weaker and has a lower significance level (OR=0.83 and $p<0.05$ for the new degree vs. OR=0.80 and $p<0.001$ for the DipSW), suggesting that gender variations are still significant in the new degree but perhaps to a lower extent than that observed during the DipSW.

Table 2 Results of binary regression model examining the association between different characteristics and the probability of being a GYO student since the introduction of the new degree, 2003-2007

\begin{tabular}{|c|c|c|c|c|}
\hline \multirow[b]{2}{*}{ Explanatory variables in the model } & \multirow[b]{2}{*}{ Sig. } & \multirow{2}{*}{$\begin{array}{l}\text { Odds } \\
\text { Ratio }\end{array}$} & \multicolumn{2}{|c|}{ 95.0\% C.I. for Odds Ratio } \\
\hline & & & Lower & Upper \\
\hline Education (ref: Degree) & $<0.001$ & & & \\
\hline O level or equivalent & 0.110 & 0.80 & 0.62 & 1.05 \\
\hline A level or equivalent & $<0.001$ & 0.47 & 0.40 & 0.55 \\
\hline Diploma & $<0.001$ & 0.65 & 0.55 & 0.77 \\
\hline Cohort (ref 03-04) & $<0.001$ & & & \\
\hline 2004-05 & 0.001 & 1.41 & 1.15 & 1.73 \\
\hline 2005-06 & $<0.001$ & 1.92 & 1.57 & 2.34 \\
\hline 2006-07 & 0.038 & 1.28 & 1.01 & 1.62 \\
\hline Post vs. under graduate & 0.479 & & & \\
\hline No disability vs. any disability & 0.035 & 1.27 & 1.02 & 1.59 \\
\hline Ethnicity (ref White UK) & $<0.001$ & & & \\
\hline White other & 0.013 & 0.62 & 0.43 & 0.90 \\
\hline Asian & 0.003 & 1.49 & 1.14 & 1.94 \\
\hline Black & $<0.001$ & 0.32 & 0.26 & 0.40 \\
\hline Mixed & 0.001 & 0.54 & 0.37 & 0.78 \\
\hline Other & 0.432 & 0.69 & 0.27 & 1.75 \\
\hline Age & $<0.001$ & 1.06 & 1.05 & 1.07 \\
\hline Women vs. men & 0.024 & 0.83 & 0.71 & 0.98 \\
\hline College vs. employment based & $<0.001$ & 0.03 & 0.02 & 0.03 \\
\hline Full vs. part time & $<0.001$ & 0.37 & 0.30 & 0.46 \\
\hline
\end{tabular}

Omnibus $\chi^{2}=5395.8$, p-value $<0.001 ;$ Nagelkerke $\mathrm{R}^{2}=0.542$

Education level, ethnicity and any reported disability were all significantly associated with the probability of being seconded or sponsored for the new degree, even when controlling for all other variables. Asian students had the highest odds ratio of being on GYO schemes followed by White, White Other, Mixed, with the least likely being Black students. When compared to White students, the odds of Asian students being GYO students were one and a half times more $(p<0.001)$, while the odds of Black students being three times less $(p<0.001)$ than that for White students. However, we know that the proportion of adult social care workers (unqualified in the main) who identify themselves as Black is around 10 percent while those who are Asian are only 3 percent (Eborall and Griffiths, 2008; Hussein, 2009) and this may affect the potential pool of applicants. 
Since the new degree, those with middle-level academic qualifications were significantly less likely to be GYO students, something not observed during the DipSW cohorts. Table 2 shows that students with ' $A$ ' levels or equivalent and those with a 'diploma' before entering their courses were less likely to be GYO students than those with a degree $(O R=0.47$ and $0.65 ; p<0.001)$. On the other hand, the odds of students with the lowest levels of qualifications, ' $O$ ' level or equivalent, being GYO students did not significantly differ from those observed among students with a degree. The higher chances of those with the lowest level of prior qualifications to be on GYO schemes reflects the continued, although threatened, use of GYO activity as a tool for training experienced staff (children's or adults) who have missed educational opportunities. However, those at the other end of the spectrum with a degree were also more likely to be on GYO schemes, reflecting the trend to enroll students with proven academic potential reflecting, again, the ability to tighten admission criteria (authors).

Another characteristic significantly associated with the probability of being a GYO student since the new degree, is self-reported disability. When controlling for other variables, students reporting no disability were significantly more likely to be on GYO schemes than those reporting any forms of disability $(O R=1.27$ and $p<0.05)$. No significant association between reported disability and the probability of being on GYO schemes was observed during the DipSW.

\section{Table 3 Summary of significantly associated variables with the probability of secondment during the old DipSW and the new degree, GSCC records 1998-07}

\begin{tabular}{|c|c|c|}
\hline Explanatory variables & $\begin{array}{c}\text { DipSW } \\
1998-2004\end{array}$ & $\begin{array}{c}\text { New Degree } \\
2003-2007\end{array}$ \\
\hline \multicolumn{3}{|l|}{ Micro (personal) factors } \\
\hline Education at time of enrolment & & $* *$ \\
\hline Reported disability & & $*$ \\
\hline Ethnicity & & $* *$ \\
\hline Age at time of enrolment & $* *$ & $* *$ \\
\hline Gender & $* *$ & $*$ \\
\hline \multicolumn{3}{|l|}{ Macro factors } \\
\hline Cohort & $* *$ & $* *$ \\
\hline Programme type & $* *$ & \\
\hline Employment status & $* *$ & $* *$ \\
\hline Study mode & $* *$ & $* *$ \\
\hline
\end{tabular}

* p-value $<0.05 ;{ }^{* *}$ p-value $<0.005$ (using logistic regression models)

Table 3 summarises this section showing which variables were significantly associated with the probability of being a GYO student during the DipSW and the new degree. Strong associations $(P<0.005)$ are indicated with two stars and weaker ones $(p<0.05)$ with a single star. It is evident that there are more factors at play since the introduction of the degree that may hinder or facilitate 
the chances of a person for secondment or sponsorship and, of course, to be accepted. In addition to the macro factors, such as cohort and employment status, there are more personal (micro) factors that are associated with being on GYO schemes, noting that programme type whether under or post graduate was not significantly different. The effect of gender seems to have slightly declined since the introduction of the new degree; however, it is still significant.

\section{Discussion}

Although that this study provided a unique insight into the varying characteristics of GYO and non-GYO students it is limited to an extent by the inability to consider unsuccessful applicants to social work programmes, especially those who may have wished to have been seconded. This reflects a lack of information about prospective or successful applicants for social work training (Manthorpe et al., 2009b). However, we show that in-career training is stratified and that in England, since the introduction of the new social work degree, it is those with higher skills or educational attainment who may be becoming more likely to be accepted for social work training sponsored by employers, which may reflect general educational 'ladders' (O'Connell, 2007). This is in the context of a desire to widen participation in professional education and of equal opportunities. In June 2008 the UK government announced plans to extend Positive Action under the Equalities Bill, so that, when selecting between two equally qualified candidates, employers can 'fast track' the under-representation of disadvantaged groups (HM Government 2008). However, among government ambitions for social work, to attract and retain the 'brightest and the best' (Department for Children, Schools and Families, 2008, p.45), there is great emphasis on 'quality' as defined by academic achievements and this may explain the move from schemes of secondment (enhancing career opportunities for existing staff) to schemes of sponsorship (bringing in new recruits for specific purposes).

The analysis revealed that educational level was not significantly associated with being seconded or sponsored prior to the introduction of the new degree, suggesting that such schemes were more likely to be open to all staff regardless of educational background. Changing patterns since the introduction of the new degree may suggest a tightening in GYO selection processes or their orientation, where those who are already academically qualified stand greater chances of being seconded or it may illustrate that sponsorship opportunities are being successfully accessed by applicants with prior high levels of education. These changing trends in the selection of GYO students on the basis of academic potential have implications for widening access to the social work profession among people who have not had participated in higher education. It is wrong to assume that secondment and sponsorship are means to enhance access to the social work profession for those who have not been able to access educational opportunities. For social work educationalists this may mean that seconded or sponsored students will not necessarily need 'study skills' or support for academic work to any greater extent than other students, even though there is some evidence that a lack of foundation subject knowledge present difficulties to students with a prior degree when being assessed at postgraduate level (Worsley et al., 2009). If 
social work educators are envisaging a GYO route among a set of professional programmes then such a route may not now meet the same 'widening participation' performance targets as previously. Nonetheless, there remain a number of GYO students with few educational qualifications and it may be that social work educators will need to consider how their study skills are best met when the majority of their cohort might already be in possession of a degree. The reliance of social work educators on previous experiences in social care as a criterion for selection, either formally or informally, is being revisited by admissions officers in constructing multiple possible filters for applicants (Manthorpe et al., 2009a).

More remains to be learned about the effects of financial support for GYO students in terms of their learning experiences and well-being. A recent survey (Collins et al., 2008) found that students undertaking part-time work while studying not surprisingly faced multiple demands. The impact of this on progression and on learning experiences needs to be considered. This highlights the surprisingly limited attention to socio-economic factors and influences in social work education (Hussein et al., 2008; 2009) and exposes the limited evidence on which social work educators may draw about what pedagogical and pastoral support is most effective for which students from different socio-economic backgrounds and circumstances.

The data reveal the interacting factors that employers seem to take into account in deciding whom they wish to fund and that HEls may consider in selection processes, and, particularly, which individuals choose to apply for these forms of social work training. Some of these factors we are unable to explore, for example, length of employment, experience, personal motivations and performance. The findings that people with specific ethnicity or gender characteristics are significantly less, or more, likely to benefit from GYO schemes are worth monitoring and exploring in local contexts. Moreover, it is evident that some personal characteristics described above have become differentially associated with being seconded or sponsored since the introduction of the new degree.

In particular, the results relating to age and gender suggest that GYO schemes may have been particularly valuable and effective in enabling older staff; older or 'mature' students are described as those aged 25 years and over (Hussein et al., 2008; 2009) and men to access social work training. For older applicants these routes may have made training affordable and instilled confidence of support from $\mathrm{HEI}$ and placement. This may have fostered the diversity of age profiles on social work programmes as well as partially compensating for former inequalities of educational opportunity. Men, in particular, continue to be underrepresented as social work students and thus in the frontline of the profession, but attracted by secondment and sponsorship. Additionally, the significantly higher representation of Asian students within GYO schemes may suggest the existence of specifically targeted schemes since the new degree; because ethnicity was not significantly associated with being a GYO student during the period of the DipSW (see Table 3). As noted elsewhere, while social work is one of the few professions where there are substantial proportions of Black students, but fewer students from Asian backgrounds (Moriarty, 2008). 


\section{Conclusion}

GYO students overall tend to be older and have tended to bring more social care experience to their student role, and may be more likely to have a realistic overview of the profession. However, this analysis of a major data set shows the consequences of the trend to sponsorship or traineeship models of GYO. The perceived advantages of these schemes are that they widen the pool of available recruits to the social work profession while also increasing the levels of men and the educational attainment levels of people entering the profession. As with the two-year Diploma in Social Work, employers may find it cost-effective in a number of ways to fund graduates on shorter postgraduate degree programmes (Hussein et al., 2008). Progression (pass) rates are also higher for post-graduate programmes; suggesting that this model may be further attractive (Evaluation of Social Work Degree Qualification in England Team, 2008).

Other models, especially secondment, draw in students with different academic and social care experiences. Work remains to be done on whether positive long-term staff retention rates are associated with GYO and are linked to outcomes for people using services. The average 'career' of a practicing social worker is not long (Curtis et al., 2009).

The Equalities Bill (2008) looks set to offer stronger weight to supporting Positive Action in recruitment in England. The increasing emphasis on the need for effective workforce planning in local authorities, including having a staff profile representative of groups with which they work, confirms that GYO offers a tool for targeted workforce development. Prioritizing male GYO candidates may be controversial, given the recognition that men are overrepresented in senior positions, despite being significantly under-represented in the profession as a whole. Whilst GYO offers opportunities to address (some) gaps in workforce diversity, and to offer educational opportunities for some of those previously denied them, these objectives require direction and resources, and are not inevitable outcomes of all GYO activity. Social work education in England has considerable experience, and relative success compared to other professions, in meeting the policy aims of student quality and diversity (Evaluation of Social Work Degree Qualification in England Team, 2008). However, the recent investment in high-level graduate trainee candidates from outside the social care workforce by the Department for Children, Schools \& Families (2008) has not been accompanied by incentives to invest in other candidates. GYO's role as an element of skills and career escalators within the social care profession may be declining and there is a need to monitor the impact of these changes.

\section{Acknowledgements}

We are grateful to all those who participated in this study and to members of staff at the General Social Care Council (GSCC) for their unfailing assistance and support, especially Helen Wenman, chair of the project board. The Social Care Workforce Research Unit receives funding from the Department of Health. The views expressed in this article are those of the authors alone and are not necessarily shared by the GSCC or the Department of Health. 


\section{References}

Balloch, S. (1999) 'Education and training in social work and social care', in Balloch, S., McLean, J. and Fisher, M. (eds) Social Services: Working under pressure, Bristol, Policy Press.

Collins, S., Coffey, M. and Morris, L. (2008) Social Work Students: Stress, Support and Well-Being, British Journal of Social Work Advance Access published on November 24, 2008. doi:10.1093/bjsw/bcn148.

Coombes, R. (2005) Authorities grow their own social workers. The Guardian. 18 May 2005.

Curtis, L., Moriarty, J. and Netten, A. (2009) The Expected Working Life of a Social Worker, British Journal of Social Work, Advance Access 2009. doi:10.1093/bjsw/bcp039

Department for Children, Schools and Families (2008) 2020 Children and Young People's Workforce Strategy, London, Department for Children, Schools and Families.

Department of Health (2000) A Quality Strategy for Social Care, London: Department of Health.

Department of Health and Department for Education and Skills (2006) Options for Excellence. Building the Social Care Workforce of the Future, London: Department of Health.

Dearing, R. (1997) Higher Education in the Learning Society, London: HMSO. Dunworth, M. (2007) 'Growing your own: The practice outcomes of employment-based social work training. An evaluative case study of one agency's experience', Social Work Education, 26(2) pp.151-68.

Eborall, C. and Griffiths, D. (2008) The State of the Adult Social Care Workforce in England, 2008. The third report of Skills for Care's Skills Research and Intelligence Unit, Leeds: Skills for Care.

Evaluation of Social Work Degree Qualification in England Team (2008) Evaluation of the New Social Work Degree Qualification in England. Volume 1: Findings, London: King's College London, Social Care Workforce Research Unit.

General Social Care Council (2008) Raising standards: social work education in England, London, General Social Care Council.

Hafford-Letchfield, T. (2007) Factors affecting the retention of learners following the degree in social work at a university in the south-east of England, Learning in Health and Social Care, 6(3) pp. 170-184.

Harris, J. Manthorpe, J. and Hussein, S. (2008) What works in Grow Your Own (GYO) schemes? in England. London, General Social Care Council. Hussein S. (2009) Social care workforce profile: Age, gender and ethnicity. Social Care Workforce Periodical, Issue 2- September 2009; web published http://www.kcl.ac.uk/content/1/c6/06/18/41/SCWPIssue2FinalDraft.pdf Hussein, S., Moriarty, J., Manthorpe, J. and Huxley, P. (2008) Diversity and progression among students starting social work qualifying programmes in England between 1995 and 1998: a quantitative study, British Journal of Social Work, 38 (8), pp.1588-1609.

Hussein S., Stevens M. and Manthorpe J. (2010) International Social Care Workers in England: Profile, Motivations, experiences and Future 
Expectations, Final Report to the Department of Health, Social Care Workforce Research Unit, King's College London: London.

Hussein, S., Moriarty J. and Manthorpe J. (2009) Variations in progression of social work students in England: Using Student Data to Help Promote Achievement: Undergraduates fulltime students' progression on the social work degree. General Social Care Council, London.

http://www.gscc.org.uk/NR/rdonlyres/B5A5B087-E7B9-471C-BAAF207DA1FBE1DA/0/Progression_analysis_FT_UG.pdf (accessed 27/11/09)

Improvement and Development Agency (2007) The Future Shape of Local Authorities' Workforces, London: Improvement and Development Agency. Langlands, A. (2005) The Gateways to the Professions Report, London: Department for Education and Skills.

Manthorpe J., Moriarty J., Hussein S., Sharpe E., Stevens M., Orme J., MacIntyre G., Green-Lister P. and Crisp B. (advance access-a) Changes to admissions work arising from the new social work degree in England. Social Work Education, 209, doi:10.1080/02615470903342085

Manthorpe, J., Moriarty, J., Hussein, S., Sharpe, E., Stevens, M., Orme, J., Maclntyre, G., Green- Lister, P. \& Crisp, B. (2009a) 'Changes to admissions work arising from the new social work degree in England', Social Work Education, doi: 10.1080/02615470903342085.

Manthorpe, J., Moriarty, J., Hussein, S., Stevens, M., Sharpe, E., Orme, J., Maclntyre, G., Green Lister, P. \& Crisp, B. (2009b) 'Applications to social work programmes in England: students as consumers?', Social Work Education, doi: 10.1080/02615470903203030..

Moriarty, J. (2008) The Social Care Workforce in the UK Labour Market, Social Care Workforce Research Unit, King's College London: London. Moriarty J., Manthorpe J., Hussein S. and Cornes M. (2008) Staff Shortages and Immigration in the Social Care Sector, a paper prepared for the Migration Advisory Committee (MAC), Social Care Workforce Research Unit, King's College: London.

Moriarty, J., Manthorpe, J., Stevens, M., Hussein, S., Sharpe, E., Orme, J., Maclntyre, G., Green Lister, P. and Crisp, B.R. (2010) A depth of data: research messages on the state of social work education in England, Research Policy and Planning.

Noble, J., Manthorpe, J. and Harris, J. (2009) The Grow Your Own Toolkit, London, General Social Care Council.

O'Connell P (2007) 'Who generally trains? The effects of personal and workplace characteristics on training at work'. In Lassnigg, L., Burzlaff, H., Larssen, M., and Rodriguez, D. (eds.) Lifelong Learning: Building Bridges Through Transitional Labour Markets, Apeldoorn, Belgium, Het Spinhuis, pp. 87-105.

Payne, M. (2005) The Origins of Social Work: Continuity and Change, Basingstoke, Palgrave.

Professional Social Work (2004) 'Grow your own: the graduate way',

Professional Social Work, July, pp. 24-25.

HM Government (2008) The Equality Bill, Government response to the Consultation, ,Presented to Parliament by The Lord Privy Seal, Leader of the House of Commons and Minister for Women and Equality by command of Her 
Majesty, London Cm 7454 http://www.official-

documents.gov.uk/document/cm74/7454/7454.pdf (accessed 27/11/09).

Stanley, N., Ridley, J., Manthorpe, J., Harris, J. and Hurst, A. (2007)

Disclosing Disability: Disabled students and practitioners in social work, nursing and teaching. London: Disability Rights Commission.

www.maintainingstandards.org/files/Disclosing\%20Disability\%20Report.pdf (accessed 27/11/09).

Wallis-Jones, M. \& Lyons, K. (2001) 1999 Employment Survey of Newly Qualified Social Workers: Final Report. London: University of East London.

Worsley, A., Stanley, N., O'Hare, P., Keeler, A., Cooper, L. and Hollowell, C. (2009) Great Expectations: The Growing Divide between Students and Social Work Educators, Social Work Education, Advance access, published 12 January 2009, doi:10.1080/02615470802512697 